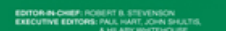

\section{Integrating multiple perspectives on the human- nature relationship: A reply to Fletcher 2017}

\section{Matthew Zylstra, Karen Esler, Andrew Knight \& Lesley Le Grange}

To cite this article: Matthew Zylstra, Karen Esler, Andrew Knight \& Lesley Le Grange (2019) Integrating multiple perspectives on the human-nature relationship: A reply to Fletcher 2017, The Journal of Environmental Education, 50:1, 1-10, DOI: 10.1080/00958964.2018.1497582

To link to this article: https://doi.org/10.1080/00958964.2018.1497582

曲 Published online: 14 Dec 2018.

Submit your article to this journal

Џll Article views: 243

View Crossmark data ¿ 


\title{
Integrating multiple perspectives on the human-nature relationship: A reply to Fletcher 2017
}

\author{
Matthew Zylstra ${ }^{\mathrm{a}, \mathrm{b}}$ (D), Karen Esler ${ }^{\mathrm{c}, *}$ (D), Andrew Knight ${ }^{\mathrm{d}, \mathrm{e}, \mathrm{f}, \neq}$ and Lesley Le Grange \\ ${ }^{a}$ EarthCollective Research, Sunshine Coast, Queensland, Australia; b Organisation for Noetic Ecology, \\ Garden Route, South Africa; 'Department of Conservation Ecology \& Entomology, Stellenbosch University,

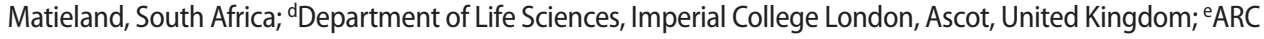 \\ Centre of Excellence in Environmental Decisions, The University of Queensland, St. Lucia, Queensland, Australia; \\ fDepartment of Botany, Nelson Mandela University, Port Elizabeth, South Africa; ${ }^{9}$ Department of Curriculum Studies, \\ Stellenbosch University, Matieland, South Africa
}

\begin{abstract}
The concept of "connectedness with nature" is increasingly used in environmental and sustainability discourse. However, this construct has also been critiqued and proponents charged with harboring an ambivalence that paradoxically reinforces a sense of separation from "nature". We respond to one critique by demonstrating that whilst problematizing aspects of "connectedness with nature" has merit, selective use of examples misconstrues efforts in this field, undermines common ground and conflates theoretical conceptualizations with practical implementation. In addressing problems of perception and praxis, we emphasize the primacy of direct experience in shaping ways of knowing and recommend integral ecology (based on Wilber's integral theory) as an inclusive framework for attending to multiple perspectives on the human-nature relationship.
\end{abstract}

\section{KEYWORDS}

Human-nature relationship; integral ecology; nature connectedness

\section{Introduction}

Recent reviews of the "connectedness with nature" (CWN) or "human-nature connection" (HNC) construct find that progress has been made in furthering conceptual understanding, measurement and application of the construct in ways that positively support the cognitive, emotional and (bio) physical aspects of human-nature interactions (Ives et al., 2017; Restall \& Conrad, 2015; Zylstra, Knight, Esler, \& Le Grange, 2014). However, Ives et al. (2017, p. 106) found that research on the topic has largely focused on CWN/HNC as "mind", as "experience" and as "place" and is characterized by "a plurality of disciplinary and conceptual perspectives, language, methods and research approaches" that has fragmented literature and perhaps limited the effectiveness of practical applications in the field. Greater effort is therefore needed toward transdisciplinary research that explores how $\mathrm{CWN} / \mathrm{HNC}$ research can: (i) pursue greater cross-pollination and integration of methods and approaches; (ii) extend beyond individuals (in predominantly Western societies) so as to better inform socially and culturally relevant strategies promoting environmentally responsible behavior; (iii) move beyond local scales so as to be useful to (conservation) policy, planning and management; and (iv) increase guidance for implementation in, e.g. environmental education and sustainability interventions aimed at children and adults (Ives et al., 2017; Restall \& Conrad, 2015; Zylstra et al., 2014). Fletcher (2017) presents a needed disciplinary perspective on CWN through the lens of political ecology with important arguments

CONTACT Matthew Zylstra matt@earthcollective.net 0 Sustainability Research, EarthCollective, Sunshine Coast, Australia ${ }^{*}$ Centre for Invasion Biology, Stellenbosch University, Matieland, South Africa.

tThe Silwood Group, London, United Kingdom.

This article was originally published with errors, which have now been corrected in the online version. Please see Correction (http://dx.doi.org/ 10.1080/00958964.2019.1569443).

() 2019 Taylor \& Francis Group, LLC 
that remind us of the social-cultural constructions that inevitably influence praxis in this field. We welcome such input, though clarification is required to ensure useful direction emerges from this discussion.

Fletcher's (2017, p. 1) primary assertion is that the concept of "connection with nature" as used in environmental education paradoxically reinforces a sense of separation from "nature" and thus requires greater investigation. Whilst this may be true within certain contexts, we challenge some of Fletcher's (2017) assertions in terms of how supporting evidence is portrayed and question whether political ecology alone is likely to deepen our understanding of the human-nature relationship. Without discounting the political ecology viewpoint, we propose a more inclusive integral approach for framing future dialog around human-nature connectedness and seek to provide a pragmatic roadmap to guide educators in navigating contested terrains.

\section{Framing CWN using a straw man}

Fletcher (2017) takes issue with conceptualizations made in our review of CWN (Zylstra et al., 2014). The most pertinent - and perhaps the primary thrust of Fletcher's (2017) article - relates to the "anthropocentric human construction [of "nature"], driven by and entrenched in a human-nature binary" (Dickinson, 2013, p. 14-15 in Fletcher 2017, p. 4). Fletcher (2017), p. 4) acknowledges that he does not intend to single us out for our apparent "ambivalence". However, in pursuit of problematizing, Fletcher (2017) focuses heavily on conceptualizations (or "definitions" as he terms them) of "nature" presented in our review (Zylstra et al., 2014) concluding that:

Hence, in the same discussion we find three simultaneous yet mutually exclusive definitions of the common term: (1) nature as an entity in the world excluding humans; (2) nature as an entity including humans; (3) nature as not an entity at all but rather a culturally specific conceptual construction (Fletcher 2017, p. 4)

We acknowledge that the different representations and contestations of "nature" could have been more thoroughly interrogated in the prefacing terminology section of our review. However, in citing our text out of its necessary chronology and context, Fletcher (2017) creates somewhat of a straw man argument that distorts our epistemological position. The charge of three simultaneous definitions is erroneous. Only one is presented and we preface this with a repudiation that Fletcher (2017) misinterprets as another "definition":

"Nature" is largely a social-cultural construction and its conceptualization will vary across-and inevitably be influenced by-such contexts, including disciplinary epistemologies. Readers should remain mindful of what is "nature" when reflecting on this review's implications (Zylstra et al., 2014, p. 121)

We state that this conceptualization of "nature" is paradoxical and problematic in perpetuating the "human/nature divide" (Zylstra et al., 2014, p. 121).However, Fletcher (2017) overlooks the purpose of a review, which is to synthesize and accurately and precisely present the terminology and nomenclature that have currency in literature.

After defining the root "connect", we address the various CWN terminologies in use (e.g. connection to nature, nature connection) noting explicitly that:

We prefer "connectedness with nature" (CWN) instead of "connectedness to nature" because it evokes the subtle yet important idea that (1) humans are already an intimate part of nature and (2) that the state imbues a sense of reciprocity and mutualism (Zylstra et al., 2014, p. 121-122).

Yet Fletcher (2017) reproaches us for providing another mutually exclusive "definition" of nature that clearly was not our intention. Rather, and in support of Fletcher's (2017) broader thesis, we were attempting to alleviate the human-nature binary by reflecting on current terminology and specifically proposing a more precise term that we believe narrows the conceptual divide between people and nature. It is true that many definitions used in the CWN/HNC literature either leave "nature" undefined (see Ives et al., 2017 who note such absences) or portray "nature" as the non-human biophysical environment, despite a long history of debate with multiple interpretations and definitions in use across the fluid social-ecological spectrum (Cleary, Fielding, Bell, Murray, \& Roiko, 2017; Hartig, Mitchell, de Vries, \& Frumkin, 2014). In this vein, we proposed a working definition of CWN as being: 
a stable state of consciousness comprising symbiotic cognitive, affective, and experiential traits that reflect, through consistent attitudes and behaviors, a sustained awareness of the interrelatedness between one's self and the rest of nature (Zylstra et al., 2014, p. 126)

Fletcher (2017) appears to overlook pertinent material in our review that tempers some of the criticisms leveled. For example, we explicitly recognize that "the call to reconnect seeks to overcome peoples' general perception as being separate from, and typically outside and above, nature and ecology (e.g., food-webs)", noting that the "blind spot" of being unable to see oneself as part of nature is a "key contributor to ongoing environmental destruction" (Zylstra et al., 2014, p. 123). We highlight that the human/ nature "hyperseparation" embedded in the Western ${ }^{1}$ discourse is linked to pervasive and largely subconscious)cognitive assumptions which split a unified relational and subjective 'reality' into an absolutist objective 'Reality' (Sewall, 1999; Zylstra et al., 2014). We review drivers behind the Westernized "disconnect" from nature and present a typology of this physical and psychological separation (Zylstra et al., 2014, p.122), emphasizing that "all drivers are likely to have been influenced by - or are a result of - cultural norms or discourses" and may stem from entrenched historical narratives (Zylstra et al., 2014, p. 122). Ultimately, we tie this to a pervasive "crisis in consciousness" fueled by, among other factors, ingrained forms of dualistic thought (Zylstra et al., 2014, p. 123).

Many of the practices for bolstering CWN/HNC detailed elsewhere in our review (Zylstra et al., 2014) are designed specifically for the purpose of encouraging a worldview that sees human nature and non-human nature as an inseparable relationship. Yet we still agree, as Fletcher (2017), p. 4) also points out in citing Argyrou (2005), that the conceptual separation remains since "in order to occupy the vantage point from which one can perceive this unity one must necessarily stand apart from the unity itself."

Given its context and aims, our review is not tainted with the "deep-seated ambivalence" charged by Fletcher (2017). We also doubt that other scholars active in conceptualizing CWN/HNC harbor mixed feelings about the human relationship with "nature". Many descriptions of CWN recognize the importance of an expanded self-construct which encompasses, and reciprocates with, all life-forms, biotic and abiotic (Bragg, 1996; Nisbet, Zelenski, \& Murphy 2009; Tam, 2013). For example, Schultz's (2011) Inclusion of Nature in Self Scale, a forerunner to the burgeoning CWN field, defines CWN as the degree to which an individual includes "nature" within their cognitive representation of "self" that creates an interdependence with nature (Bragg, Wood, Barton, \& Pretty, 2013; Restall \& Conrad, 2015). ${ }^{2}$ Conceptually, these spectrums or degree of relationship seek to transcend the human-nature dichotomy highlighted by Fletcher (2017).

\section{Problems in praxis}

We contend that an important distinction needs to be made between theory and practice, and the extent to which CWN is popularized (and thus simplified) for diverse audiences. As Fletcher (2017) posits, it is probable that the implementation of environmental education practices perpetuates the "nature-culture" divide. In our experience, and as Dickinson (2013) also finds ${ }^{3}$, formal (e.g. class-based) environmental education allows little room for the reflexive orientations and interrogations needed to tackle the "big ticket" challenges of the colonizing framing of Eurocentric post-modernity (in creating a nature-culture dichotomy) and the "stealth practices" of neoliberalism (Payne, 2016, p. 175). We have observed that constraints of time, resources, field excursions, and curricula expectations and trends toward online distance learning tend to corral educators back toward traditional (pedagogically familiar and "safe") didactic approaches that preference fact-filled education about "the natural environment" through the dominant system (e.g. a materialist or scientific framing/naming lens) of enculturation. Experiential exploration and interrogation may be sacrificed alongside the contemplative, reflective and embodied practices (as advocated by CWN scholars) needed to motivate personal and social change (Dickinson 2013; Ashwell 2010 and Zylstra et al., 2014, p. 128 for examples of practices).

Under such scenarios, it is understandable that a praxis for environmental education fails to "address the cultural, economic, and political systems that contribute to alienation, notably concerning issues... [such as] poverty, racial segregation, cultural alienation, environmental racism, and rampant 
overconsumption" (Dickinson 2013, p. 330). Similarly, one is unlikely to find reflection on the "political and economic structures and forces influencing natural resource use and degradation ...particularly the neoliberal capitalist system" that Fletcher's $(2017$, p. 6) hopes for. Whilst we agree with the premise, we question how many environmental educators seeking praxis: (i) are aware of their own lens and framing; (ii) consider the tackling of systemic behemoths to be within their remit or realm of influence; or (iii) believe that tackling such structures and forces with learners is the most effective approach for instilling a felt sense of relatedness and responsibility toward all of nature, human and non-human.

\section{Problems in perception}

Educators may advocate a version of the monistic naturalism articulated by Spinoza (1677/2001) that ontologically we are part of nature and do not hold a privileged place in the cosmos. If so, why do learners routinely express relationships to nature in terms of "connection" or "disconnection"? Why can everyday lived experience oscillate between feeling part of, and separate from, nature? How can we reconcile a oneness with nature with humans' unique and far-reaching capability of acting in ways that destroy life on earth? What does "being a part of nature" really mean in thought, feeling and action? These are foundational questions that environmental education needs to continuously revisit.

As many other authors have long highlighted, "nature" and the conceptual and experiential "human-nature" distinction is complex, multi-layered, deeply-rooted in cultural discourse (including language and metaphor) and subjective experience and therefore contains ambiguities, contradictions and inconsistencies that undermine the perception and experience of a more unified human-nature relationship. There is a well-recognized gradual Western historical, cultural and psychological split between the "in-here" and "out-there" and this dichotomy manifests as the divide we perceive between ourselves and non-human nature (Sewall 1999; Dickinson 2013). Einstein was more forthright in his summation that, despite Man [sic] being "part of a whole", "He [sic] experiences himself [sic], his [sic] thoughts and feelings as something separated from the rest - a kind of optical delusion in consciousness... a kind of prison for us" (in Bekoff, 2014, p. 12).

All this discussion alerts us to a problem of (Westernized) perception wherein lies a persistent dilemma of how to reconcile the tripartite dissonance between the background knowing (cognitive) we are biologically and physically part of nature, the sporadic feeling (affective/experiential) of being deeply part of nature against our routine destructive individual and collective actions (behavioral) that are at odds with a harmonious relationship that would meet human needs and contribute to the persistence of the social-ecological system. For example, a study of American adults showed that even people who viewed themselves as part of nature still saw natural landscapes as those which were free of human interference (Vining, Merrick, \& Price, 2008).

We therefore empathize with Fletcher's (2017) problematizing of "nature" as generally being used in opposition to "humans" or "society" and his preference for Latour's (2004) focus on "assemblages" of human and nonhuman "actants". However, we agree with Castree and Head (2008, p. 1256) in questioning whether, however problematic, there is a better way in English to speak for the nonhuman world (noting also that many languages do not have an equivalent word for "nature"). This is particularly relevant to environmental educators and on-ground practitioners who may be unable to jettison concepts of "nature" and "culture" anytime soon. As Payne (2016, p. 175) notes, "the universalizing implications of homogenizing and conflating nature and culture, and their environments, and humans and nonhumans" have profound theoretical, pedagogical, and practical implications for environmental education, research and policy, especially if "nature" is gradually made invisible or non-existent in the forming of social-ecological relationships.

We therefore concur with Cronon and Cronon (1996, p. 22) that “...we must think long and hard about the nature we carry inside our heads". But how can educators explore these "natures" from multiple perspectives? What approach can educators use to inclusively frame, guide and navigate disciplinary demands without blindly favoring one perspective of "nature" over another? 


\section{Toward a unifying approach}

We share many of Fletcher (2017) concerns. However, we believe that CWN/HNC and environmental education scholarship would be more effectively served by a meta-framework that enables us to map - as a means of highlighting critical "absences" or "silences" (sensu Payne, 2016) - the various ontological epistemological methodological terrains which we all inhabit and inevitably move between.

Wilber's (1995) integral theory appears to provide a more impartial and unifying background approach toward addressing social-environmental issues and, ultimately, multiple perspectives on the human-nature relationship. The All Quadrants All Levels (AQAL) model (Figure 1) recognizes four irreducible perspectives or dimensions of reality, i.e. subjective, intersubjective, objective, and interobjective, whereby the subjective ('I') quadrant consists of first-person perspectives (experiential phenomena), the intersubjective ('WE') consists of second-person moral perspectives (cultural phenomena); the objective ('IT') consists of third-person scientific and natural perspectives (behavioral phenomena); and the interobjective ('ITS') consists of third-person scientific, political and natural systems perspectives (social phenomena).

According to integral theory (and subsequently expounded into "integral ecology", sensu EsbjörnHargens \& Zimmerman, 2009), these four quadrants represent irreducible perspectives that must be consulted when attempting to fully understand any issue or aspect of reality (Esbjörn-Hargens \& Zimmerman, 2009). The quadrants remind us of the dimensions of reality that are present in every moment in human and non-human life, and which can equally be viewed from the interior (subjective) or exterior (objective) and/or from individual (singular) or collective (plural) perspectives of humans and non-humans.

The political ecology standpoint as articulated by Fletcher (2017) and others is primarily situated in the lower-right quadrant (Figure 1). This discipline's emphasis on the socio-political framing of issues, power relations within structure and systems, and discourse analysis in addressing environmental problems is an important perspective and has necessarily broadened discussion on social-ecological matters.

However, critiques have expressed concern about political ecology's tendency toward overt anthropocentrism - even human exceptionalism - by becoming blind to the ecology in "political ecology", i.e. that political decisions are ultimately shaped by the primordial or "first nature" that existed before humans (Payne, 2016; Srinivasan \& Kasturirangan, 2016; Menon \& Karthik, 2017). From an integral approach, what we see here is a privileging of the human perspective, such that all four-quadrants are insufficiently addressed through the eyes of non-human nature. To retrieve the agency for the non-human world, it has been suggested that more direct engagement with, and immersion in the lives of, the non-human is needed, such that we might make the "ontological turn" that allows us to depart from the worlds that we inhabit, examine how human-nature relations are co-constituted, and become attentive and sensitive to the agency of the non-human world, e.g. how might a plant or animal feel about a proposed action (Menon \& Karthik, 2017). In drawing on Wilber (2000), Mattson's (2009) critique of political ecology (with specific relevance to environmental education) notes that political ecology has previously demonstrated bias toward the exterior domains (upper and lower-right quadrants), neglecting the interior human dimensions - that Dickinson (2013) advocates and Payne (2016) highlights as an "absence" in critical environmental education- such as contemplative self-awareness, values, purpose, meaning, emotional expression, deeper sensorial and "somaesthetic" experiences, memories, and reflections on personal and cultural connections with nature (Mattson, 2009; Wilber, 2000). These subjectivities are instead often reduced to more rational and purportedly objective empirical systemic processes "obscuring a foundational ontological dimension" (Mattson, 2009, p. 222) of the inner human condition and one's perception and experience of the human-nature relationship (upper-left quadrant). It has been recognized that political ecology "does not have a unifying notion of human well-being" (Menon \& Karthik, 2017). This may be in part due to a relative neglect of the individual human experience with non-human nature (i.e. psychological and phenomenological, upper-left quadrant) as well as acknowledging the multitude of ways that individuals positively respond to contact with non-human nature (i.e. physiological and neurological, upper-right quadrant). It is in this realization that the discipline may be able to more constructively explore how CWN (which has been positively linked to multiple human well-being benefits, 


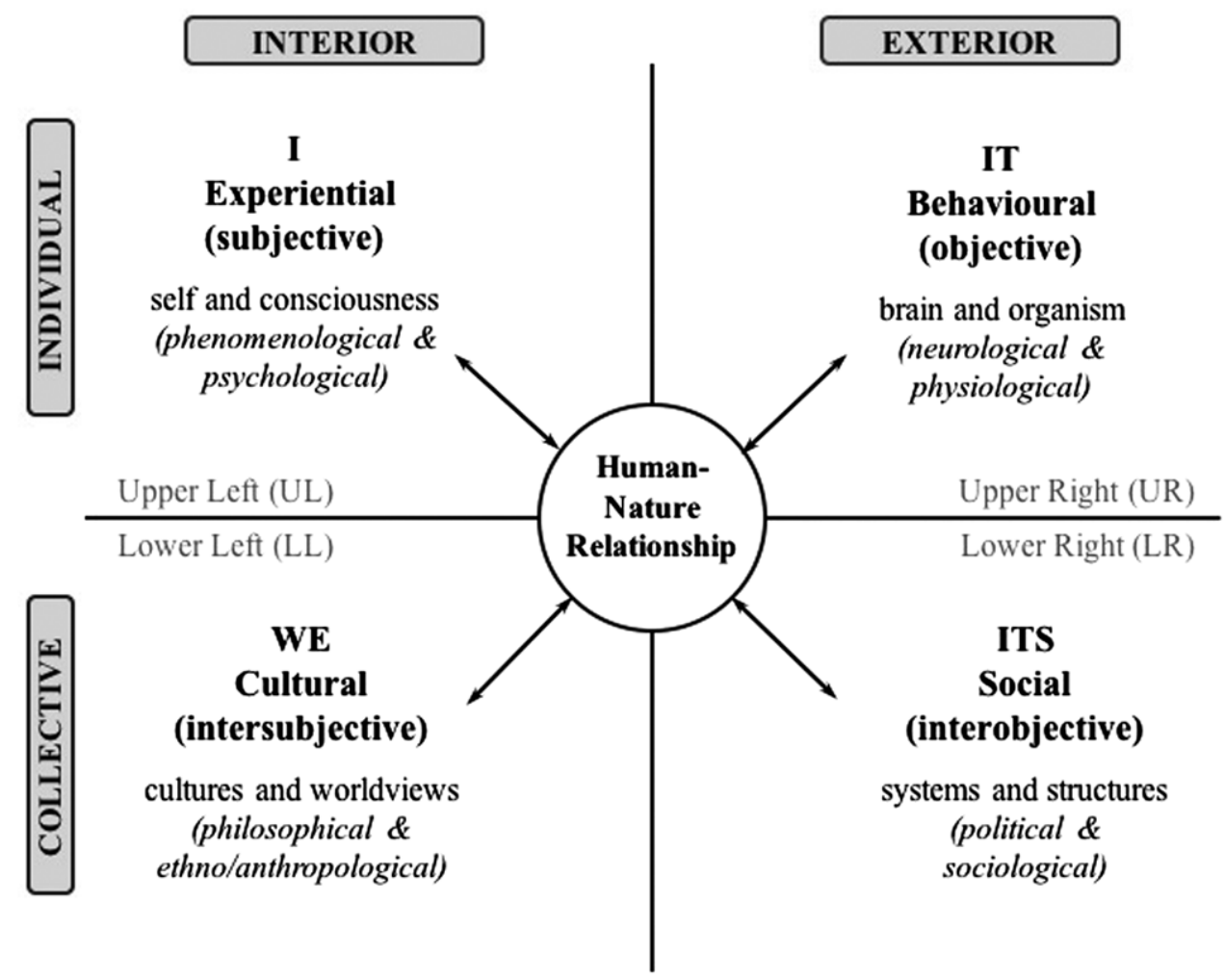

Figure 1. The four quadrant model as applied to the human-nature relationship from the human perspective (adapted from EsbjörnHargens \& Zimmerman, 2009; Wilber, 1995).

see Zylstra et al., 2014 and, more recently, Bratman, Daily, Levy, \& Gross, 2015; Soga \& Gaston, 2016; Cleary et al., 2017; Ives et al., 2017; as well as the notion of "collective identity" ${ }^{\text {) }}$ might find synergy with a political ecology standpoint.

Whilst these interior terrains with which CWN engages are highly relevant, they are in themselves also insufficient. In their exploration of integral ecology, Esbjörn-Hargens and Zimmerman (2009) address the question of "one with which nature?" and suggest that it depends on at least three elements: what we mean by "one with" (or "part of" or "connected with"), which developmental level we are operating from (roughly traditional, modern, postmodern) and what we mean by "nature". Specifically,

"Being one with nature" can refer to a particular kind of experience, a specific set of behaviors, a certain type of relationship with other beings, or a particular role within eco-social systems. In fact, an individual can be one with nature in all 4 terrains: behavior, experience, cultural, and systems. It is possible to feel one with nature but not act as one with nature. It is possible to be part of systems that are one with nature but a member of a culture that is not, and so on. We need a "tetra-mesh" understanding of "being one with nature". It is not enough to have only a phenomenological experience of unity with the natural world (Esbjörn-Hargens \& Zimmerman, 2009, p. 277).

It is therefore imperative to also examine the lower-left quadrant of "WE" (Figures 1 and 2) and explore the extent to which intersubjective experiences - as informed by cultures and worldviews - influence the human-nature relationship. This speaks directly to Payne's (2016) desire to see ontological epistemological belief and faith systems, traditions, and cosmologies better addressed in environmental education. Exploring this quadrant also responds to Dickinson's (2013, p. 331) call for encouraging learners and educators alike to "step outside the story into which we have been cast... and enter into a story with a different plot" (Cronon \& Cronon 1996, p. 22) by recognizing the underlying cultural beliefs that problematize the so-called "nature-deficit disorder" or "disconnect" and the ways in which we enact environmental education with particular social-cultural framings. 


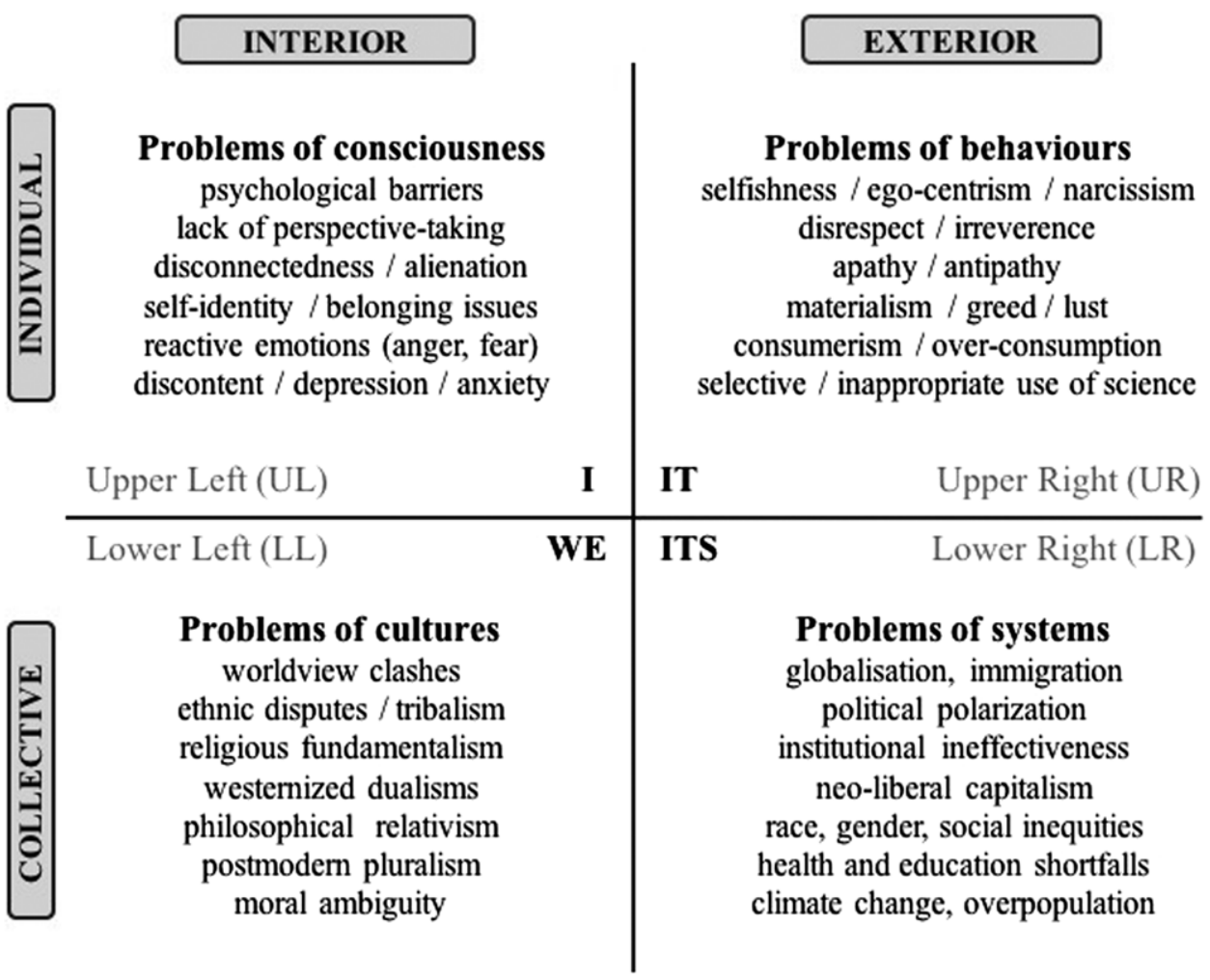

Figure 2. The four terrains of social-ecological problems (with example issues) using the four-quadrant model of integral theory (adapted from Mattson 2009).

Ambivalence about the human-nature relationship and our "connection" to it may therefore arise when we conflate terrains (i.e. quadrants) and lack clarity on which terrain we are situated in or speaking for. In a praxis for environmental education, ambivalence may also surface when we assume we are pedagogically engaged with a purportedly "objective" scientific view of the human-nature relationship (e.g. the "exteriors" of the upper left and upper-right quadrants) but may in fact be conveying a worldview (lower left intersubjective quadrant) that is at odds with learner's own worldviews (e.g. from religious or cultural backgrounds with a contrasting view of the human-nature relationship or even of human origins and creation itself). In summary and, as Payne (2016, p. 172) observes:"EE has been notoriously silent about the practical, material/theological, symbolic/ritualized, everyday role of religion".

The integral framework therefore serves as a map - a conceptual reminder - of which perspectives we are privileging at the possible expense of others. "Realities" are understood as a dynamic interaction between the who, how and what, whereby different approaches to ecology are the result of a spectrum of perspectives ("the who"); using a variety of methods ("the how"); to explore different aspects of the four terrains ("the what"; Esbjörn-Hargens \& Zimmerman, 2009).

Similarly, it allows us to position the plethora of perceived problems in a way that helps orient which disciplinary lens or methodology may be best placed to spearhead dialog and possible solutions (Figure 2). For example, in promoting a political ecology of environmental education, Fletcher (2017) positions problems and solutions in the lower-right quadrant whilst Dickinson (2013), in advocating for alternatives alongside contemporary natural science approaches and discourses, is primarily seeking to elevate the importance of the interior dimensions, particularly the upper-left quadrant, while reflecting on causes found in the lower-left quadrant. Methodological pluralism is therefore required to integrate and embrace alternative perspectives so as to overcome the tendency of only doing research, practice and thereby praxis according to one's preferred lens (Esbjörn-Hargens \& Zimmerman, 2009). 
Integral ecology therefore provides a transparent framework for acknowledging, categorizing and weaving fragmented perspectives on the human-nature relationship by accounting for the diverse worldviews within individuals, communities, and cultures - each with its specific form of mutual understanding (Esbjörn-Hargens \& Zimmerman, 2009). In a sense, it allows for the legitimate coexistence of multiple opposing realities.

Integral ecology highlights that the environment and its various dimensions are revealed differently depending on the mode of inquiry used to investigate it and so supports us in becoming increasingly reflective of what we are engaging with, who we are as we are engaging, and how we are doing the looking (EsbjörnHargens \& Zimmerman, 2009). Specifically, it allows for greater epistemological pluralism and shines a light on the often neglected importance of personal experience, meaning-making, moral development and evolution of consciousness as part of a cognitive-affective-behavioral transformation that is critical in addressing the problems spawned by cultural conditioning and systemic structures (Esbjörn-Hargens \& Zimmerman, 2009; Mattson, 2009; Wilber, 2000). In effect, integral ecology is an ecology of perspectives that unites consciousness, culture, and nature in service of sustainability (Esbjörn-Hargens \& Zimmerman, 2009).

For all its merit, the integral theory approach is not immune to critique. In his commentary on integral ecology, Greenway (2011, p. 159) ultimately asks "can a bigger map save us?” Specifically, questions arise as to who the map is for and how we can realistically expect environmental educators to embrace such an approach in praxis. Environmental education appears to be increasingly tasked with any or all of: improving eco-literacy, field awareness and local place-based ecological knowledge; building skills and capacity for addressing complex environmental issues; fostering critical thinking reassessing cultural and historic narratives, reflection and participation; encouraging sustainable action through informed lifestyle choices; cultivating personal growth; and empowering learners to make pro-active contributions toward positive social-political change (Zylstra et al. 2014; Ashwell 2010). Across this vast and scattered portfolio, there is a real danger of environmental education "becoming a salvation narrative for the twenty-first century, aiming to address all the issues in the world" (Ashwell, 2010, p. 45).

Indeed, should these increasingly all-encompassing demands be laid at the feet of the already marginalized and overburdened environmental education sector? From an integral perspective, education should never be separated from its environs, its place and its context: education is always situational (Gruenewald, 2003, 2005). In this respect, we advance Fletcher's (2017) charge that "connection with nature is an oxymoron" by using the same logic to suggest that "environmental education" is equally contradictory. If we are committed to healing fractured approaches then we need curriculum-wide integral education that explores experiential-behavioral-cultural-systemic perspectives within and across all terrains of the social-ecological spectrum.

Ultimately, all human behavior, cultural worldviews, systems and representations of "truth" and "reality" are grounded in - and are expressions of - direct human experience. Since the interiors feed and inform the exteriors, we cannot describe a world that is not within human experience/awareness while we have no way of being outside of it. A focus on individual/personal and collective/group consciousness (i.e. awareness as formed through cumulative experiences) is thus self-evident and needs to be elevated in any approach that seeks durable social-ecological change. This characterizes noetic ecology: a field that elevates the primacy of consciousness to rigorously explore the full range of human experience - including different ways of knowing and relating with all "nature".

Ultimately, we trust that any such approach furthers dialog and understanding of the multiple perspectives brought to bear on human-nature relatedness and to illuminate those being marginalized. As Greenway (2011, p. 163) also hopes, it may invite "our participation, encouraging a "coalescence of minds" - perhaps a guide out of the splintered prison the dualistic program makes of our place... on this earth." How our sense of connectedness with all nature coalesces within and beyond this program remains to be seen.

\section{Notes}

1. Contrary to Fletcher's (2017, p. 4) claim that "the CWN perspective tends to confuse a culturally specific worldview for the human condition in general”, we state in our review's methods section (see Zylstra et al., 2014, p. 121). that: There is a general bias in literature toward Western conceptualizations of CWN, noting however that "Western" is an imprecise term which can be variously defined according to context. In this paper, we use "Western" to refer to 
the culture and philosophical tradition that has its historical roots in early European cultures (e.g., Greco-Roman, Germanic), Judaic and Christian values and Enlightenment thinking and that has shaped Anglo-European and North American society. This review, therefore, primarily focuses on CWN as relevant to persons socialized to middle-class Western values on the basis that it is widely accepted that the Western culture is largely responsible for fueling and exacerbating humanity's separation from nature. However, since Western culture (and its discourse) has been exported through colonization and globalization, Western (and Westernized) worldviews are no longer geographically confined to Europe and its former colonies. In this regard, implications of this review are cross-culturally relevant, particularly since contemporary CWN draws much inspiration from non-Western (e.g., Eastern, Indigenous) traditions (Zylstra et al., 2014, p. 121). This does not imply that Westernized or non-Westernized worldviews are unitary, homogonous or monolithic nor that all non-Western approaches may necessarily guide CWN application.

2. The CWN construct is more than cognitive and conceptual: it also widely considered to include affective (e.g. emotional bonds with nature sensu Kals, Schumacher, \& Montada, 1999; Mayer \& Frantz, 2004; Tam, 2013), experiential (e.g. frequency, familiarity and comfort in nature, sensu Menon \& Karthik, 2009), behavioral dimensions (intention and commitment to act responsibly toward the natural environment sensu Frantz \& Mayer, 2014; Kollmuss \& Agyeman, 2002; Restall \& Conrad, 2011). Collective identity has also been highlighted for inclusion on the basis of 'nature' being a shared community to which humans belong, sensu Ashmore, Deaux, \& McLaughlin-Volpe, 2004; Restall and Conrad, (2015). See Zylstra et al., (2014) for a review of the CWN construct.

3. As Dickinson (2013, p. 318-319) highlights, we also wish to emphasize that:

Environmental education (EE) initiatives vary greatly, with radically diverse approaches and assumptions about human-nature relationships. A plethora of EE and nature-related programs abound - from mainstream... science-based EE curricula to less traditional human-nature reconciliation initiatives.

\section{ORCID}

Karen Esler (iD http://orcid.org/0000-0001-6510-727X

Matthew Zylstra iD https://orcid.org/0000-0002-2881-4984

Andrew Knight (iD https://orcid.org/0000-0002-6563-0500

Lesley Le Grange (ID https://orcid.org/0000-0002-7096-3609

\section{References}

Argyrou, V. (2005). The logic of environmentalism: Anthropology, ecology, and postcoloniality. New York: Berghahn.

Ashmore, R. D., Deaux, K., \& McLaughlin-Volpe, T. (2004). An organizing framework for collective identity: Articulation and significance of multidimensionality. Psychological Bulletin, 130(1), 80-114. doi:10.1037/0033-2909.130.1.80

Ashwell, A. N. (2010). Identity and belonging: urban nature and adolescent development in the City of Cape Town. PhD dissertation. University of Cape Town, Cape Town.

Bekoff, M. (2014). Rewilding Our Hearts: Building Pathways of Compassion and Coexistence. Novato: New World Library.

Bragg, E. (1996). Towards ecological self: Deep ecology meets constructionist self- theory. Journal of Environmental Psychology, 16(2), 93-108.

Bragg, R., Wood, C., Barton, J., \& Pretty, J. (2013). Measuring connection to nature in children aged 8 -12: A robust methodology for the RSPB A short report for RSPB.

Bratman, G., Daily, G., Levy, B., \& Gross, J. (2015). The benefits of nature experience: Improved affect and cognition. Landsc Urban Plan, 138, 41-50.

Castree, N \& Head, L. (2008). Culture, nature and landscape in the Australian region. Geoforum, 39(3), $1225-1257$. doi:10.1016/j.geoforum.2007.10.013

Cleary, A., Fielding, K. S., Bell, S. L., Murray, Z., \& Roiko, A. (2017). Exploring potential mechanisms involved in the relationship between eudaimonic well-being and nature connection. Landscape and Urban Planning, 158, 119-128. doi:10.1016/j.landurbplan.2016.10.003

Cronon, W. (1996). Forward to the paperback edition. In W. Cronon, (Ed.), Uncommon ground: Rethinking the human place in nature (pp. 19-22). New York: W. W. Norton.

Dickinson, E. (2013). The misdiagnosis: Rethinking "Nature-deficit Disorder." Environmental Communication, 7(3), 315335. doi:10.1080/17524032.2013.802704

Esbjörn-Hargens, S., \& Zimmerman, M. E. (2009). Integral Ecology: Uniting multiple perspectives on the natural world. Boston \& London: Integral Books (Shambhala Publications).

Fletcher, R. (2017). Connection with nature is an oxymoron: A political ecology of "nature-deficit disorder." The Journal of Environmental Education, 48(4), 226-233. doi:10.1080/00958964.2016.1139534

Frantz, C. M. P., \& Mayer, F. S. (2014). The importance of connection to nature in assessing environmental education programs. Studies in Educational Evaluation, 41, 85-89. doi:10.1016/j.stueduc.2013.10.001

Greenway, R. (2011). Can a bigger map save us? A commentary on Esbjörn-Hargens and Michael Zimmerman's Integral ecology: Uniting multiple perspectives on the natural world. Ecopsychology, 3(2), 159-163. doi:10.1089/eco.2010.0045

Gruenewald, D. A. (2003). The best of both worlds: A critical pedagogy of place. Educational Researcher, 32(4), 3-12. 
Gruenewald, D. A. (2005). Accountability and collaboration: Institutional barriers and strategic pathways for place-based education. Ethics, Place \& Environment, 8(3), 261-283.

Hartig, T., Mitchell, R., de Vries, S., \& Frumkin, H. (2014). Nature and health. Annual Review of Public Health, 35(1), 207-228. doi:10.1146/annurev-publhealth-032013-182443

Ives, C., Giusti, M., Fischer, J., Abson, D., Klaniecki, K., Dorninger, C., ... von Wehrden, H. (2017). Human-nature connection: a multidisciplinary review. Current Opinion in Environmental Sustainability, 26-27, 106-113.

Kals, E., Schumacher, D., \& Montada, L. (1999). Emotional affinity toward nature as a motivational basis to protect nature. Environment and Behavior, 31(2), 178-202. doi:10.1177/00139169921972056

Kollmuss, A., \& Agyeman, J. (2002). Mind the gap: Why do people behave environmentally and what are the barriers to pro. Environmental Behaviour. Environmental Education Research, 8(3), 239-260. doi:10.1080/1350462022014540

Latour, B. (2004). Politics of nature: How to bring the sciences into democracy. Cambridge, MA: Harvard University Press.

Mattson, M. (2009). Neglected interiors: A critique of political ecology, with reference to the work of Ken Wilber. South African Journal of Environmental Education, 26, 221-231.

Mayer, F. S., \& Frantz, C. M. P. (2004). The connectedness to nature scale: A measure of individuals' feeling in community with nature. Journal of Environmental Psychology, 24(4), 503-515. doi:10.1016/j.jenvp.2004.10.001

Menon, A., \& Karthik, M. (2017). Beyond human exceptionalism: Political ecology and the non-human world. Geoforum, 79, 90-92. doi:10.1016/j.geoforum.2016.12.017

Nisbet, E. K., Zelenski, J. M., \& Murphy, S. A. (2009). The nature relatedness scale. Environment and Behavior, 41(5), 715-740. doi:10.1177/0013916508318748

Payne, P. G. (2016). What next? Post-critical materialisms in environmental education. Journal of Environmental Education, 47(2), 169-178. doi:10.1080/00958964.2015.1127201

Restall, B., \& Conrad, E. (2015). A literature review of connectedness to nature and its potential for environmental management. Journal of Environmental Management, 159, 264-278. doi:10.1016/j.jenvman.2015.05.022

Schultz, P. W. (2011). Conservation means behavior. Conservation Biology, doi:10.1111/j.1523-1739.2011.01766.x

Sewall, L. (1999). Sight and Sensibility: The Ecopsychology of Perception. New York: Tarcher/Putnam. 25(6), $1080-1083$.

Soga, M., \& Gaston, K. (2016). Extinction of experience: the loss of human-nature interactions. Frontiers in Ecology and the Environment, 14(2), 94-101.

Spinoza, B. (2001). Ethics. (W. H. White, Trans.). Wordsworth: Hertfordshire

Srinivasan, K., \& Kasturirangan, R. (2016). Political ecology, development, and human exceptionalism. Geoforum, 75, $125-128$.

Tam, K. P. (2013). Concepts and measures related to connection to nature: Similarities and differences. Journal of Environmental Psychology, 34, 64-78. doi:10.1016/j.jenvp.2013.01.004

Vining, J., Merrick, M. S., \& Price, E. A. (2008). The distinction between humans and nature: Human perceptions of connectedness to nature and elements of the natural and unnatural. Human Ecology Review, 15(1), 1.

Wilber, K. (1995). Sex, ecology, spirituality: The spirit of evolution. Boston: Shambhala.

Wilber, K. (2000). Integral Psychology: Consciousness, Spirit, Psychology, Therapy. London: Shambhala.

Zylstra, M. J. (2014). Exploring meaningful nature experience, connectedness with nature, and the revitalization of transformative education for sustaibability. PhD dissertation, Stellenbosch University, Stellenbosch. http://scholar.sun.ac.za/ handle/10019.1/86290

Zylstra, M. J., Knight, A. T., Esler, K. J., \& Le Grange, L. L. L. (2014). Connectedness as a core conservation concern: An interdisciplinary review of theory and a call for practice. Springer Science Reviews, 2(1-2), 119-143. doi:10.1007/ s40362-014-0021-3 